OPEN ACCESS

Edited by:

Eric Giannoni,

Lausanne University Hospital (CHUV),

Switzerland

Reviewed by:

Paola Elisa Cogo,

Università degli Studi di Udine, Italy Hans Fuchs,

Universitätsklinikum Freiburg,

Germany

*Correspondence: Ben Gelbart

ben.gelbart@rch.org.au

Specialty section:

This article was submitted to Neonatology,

a section of the journal

Frontiers in Pediatrics

Received: 30 June 2018 Accepted: 01 October 2018 Published: 25 October 2018

Citation:

Gelbart B (2018) Fluid Bolus Therapy in Pediatric Sepsis: Current Knowledge and Future Direction. Front. Pediatr. 6:308 doi: 10.3389/fped.2018.00308

\section{Fluid Bolus Therapy in Pediatric Sepsis: Current Knowledge and Future Direction}

\author{
Ben Gelbart ${ }^{1,2,3 *}$ \\ ${ }^{1}$ Paediatric Intensive Care Unit Royal Children's Hospital, Melbourne, VIC, Australia, ${ }^{2}$ Murdoch Childrens Research Institute, \\ Melbourne, VIC, Australia, ${ }^{3}$ The University of Melbourne, Melbourne, VIC, Australia
}

Sepsis is a leading cause of morbidity and mortality in children with a worldwide prevalence in pediatric intensive care units of approximately 8\%. Fluid bolus therapy (FBT) is a first line therapy for resuscitation of septic shock and has been a recommendation of international guidelines for nearly two decades. The evidence base supporting these guidelines are based on limited data including animal studies and case control studies. In recent times, evidence suggesting harm from fluid in terms of morbidity and mortality have generated interest in evaluating FBT. In view of this, studies of fluid restrictive strategies in adults and children have emerged. The complexity of studying FBT relates to several points. Firstly, the physiological and haemodynamic response to FBT including magnitude and duration is not well described in children. Secondly, assessment of the circulation is based on non-specific clinical signs and limited haemodynamic monitoring with limited physiological targets. Thirdly, FBT exists in a complex myriad of pathophysiological responses to sepsis and other confounding therapies. Despite this, a greater understanding of the role of FBT in terms of the physiological response and possible harm is warranted. This review outlines current knowledge and future direction for FBT in sepsis.

Keywords: fluid therapy, pediatric, septic shock, sepsis, volume responsiveness

\section{INTRODUCTION}

The worldwide burden of sepsis in pediatric intensive care in terms of morbidity and mortality remains high and is a key healthcare priority (1-3). Fluid bolus therapy (FBT) has long been the central component of resuscitation of children with sepsis (4). The role of FBT is to improve the circulating volume, cardiac output and mitigate circulatory dysfunction and organ hypoperfusion. It is the recommended forefront therapy of international pediatric and adult consensus guidelines in high-income and low-income settings (5-8). The emergence of evidence demonstrating harm associated with FBT has led to a re-evaluation of its role in sepsis resuscitation.

Data supporting current pediatric sepsis guidelines are limited. Recommendations in relation to FBT have been based on small case control studies and animal data, mostly from two-three decades ago (9-11). Few randomized controlled studies exist. The most recent 2017 ACCM/PALS guidelines recommend that $20-60 \mathrm{ml} / \mathrm{kg}$ should be administered, titrated to clinical signs of shock and discontinued at shock resolution or fluid overload (5). Fluid resuscitation (FR) for refractory shock and assessment of response is recommended within $15 \mathrm{~min}$ to which adherence has proven difficult $(12,13)$. The past two decades has seen large multicentre studies targeting optimal fluid composition $(14,15)$, goal directed therapy (16-18), fluid restrictive protocols (19-23) as well as a pivotal study of FBT vs. no FBT in African children with sepsis (24); all contributing to the current landscape. 
Clinicians aim to identify patterns of circulatory dysfunction in septic shock that include myocardial dysfunction, systemic vasodilatation, and hypovolaemia (25). This generally relies on clinical examination and non-invasive haemodynamic parameters. The challenge of investigating whether interventions that independently, or in combination with others, improve outcomes or cause harm may prove difficult (26). The complexity of assessing one component of a suite of interventions to address a multifaceted pathophysiological process will require carefully designed studies. Yet, in the face of many unanswered questions and associated harm, the imperative to investigate the role of FBT in sepsis exists.

This review outlines the current understanding of the role of FBT in children with sepsis and recent research direction.

\section{EPIDEMIOLOGY OF SEPSIS, PATTERNS OF FLUID RESUSCITATION AND OUTCOMES IN CHILDREN}

The global burden of sepsis and septic shock is high in pediatric intensive care units (PICUs) with prevalence studies suggesting mortality rates ranging from 6 to $25 \%(1,27)$. Temporal trends suggest that although prevalence may be increasing, severe sepsis mortality might be declining (2). In PICUs in ANZ, the prevalence of sepsis and septic shock is 2.9 and $2.1 \%$ respectively and accounts for over a quarter of PICU deaths (28). In the US, an observational study of septic shock in children indicated that a third of deaths occur early (1-3 days) with a high proportion occurring in previously healthy children (29). The most common causes of death being refractory shock followed by secondary organ dysfunction. In ANZ, Schlapbach et al. demonstrated that $50 \%$ of deaths from sepsis occurred within $48 \mathrm{~h}$ and that predictors of death unsurprisingly relate to presence of markers of multi-organ dysfunction (30). Pediatric sepsis mortality in low income countries range widely (31) due to definitions of shock, disease specific and population specific factors as well as differences in intensive care resources.

There are very few large scale epidemiological or randomized studies of FBT in pediatric septic shock (32). Several pediatric observational studies of the resuscitation phase of sepsis have mostly been small single center studies and compare survivors and non survivors $(33,34)$, those with or without shock (12), or protocol adherence $(13,35,36)$. Those reporting outcomes with volume or timing of FBT show varying results. Paul et al. for instance, showed that those who received $60 \mathrm{ml} / \mathrm{kg}$ of FBT within $60 \mathrm{~min}$ in the emergency department had a $57 \%$ shorter hospital length of stay than children who did not (13). Whether this relates to early recognition and implementation of a range of interventions such as early appropriate antibiotics or FBT is unclear. An audit of pediatric sepsis management from the United Kingdom showed that the initial median volume of FBT prior to intensive care is $50-60 \mathrm{ml} / \mathrm{kg}$ (12) suggesting alignment to current guidelines in the initial phase of sepsis management.

A large US adult study of the interaction between fluid administration on day 1 and mortality from sepsis showed increased severity adjusted mortality and cost for each liter above $5 \mathrm{~L}$; in the presence of shock, mechanical ventilation or both (37). Leisman et al. however, showed in an observational cohort study of adults with sepsis that less time to initiation of FBT reduced hospital mortality, ICU admission, mechanical ventilation duration and length of ICU and hospital stay. These were adjusted for measures of organ dysfunction, patient source and antibiotic administration (38). The inherent limitations in this study preclude a causal relationship however of note, no difference in hospital mortality was observed for volume of FBT until $>35 \mathrm{ml} / \mathrm{kg}$ was administered where mortality was increased. Whether improved survival relates to timely recognition of sepsis, improved bundle delivery remains unclear. There are a paucity of similar pediatric data associating outcomes with fluid resuscitation.

\section{PATHOPHYSIOLOGICAL ASPECTS OF SEPSIS AND RESPONSE TO FBT}

The pathophysiology and haemodynamic patterns in septic shock are complex, dynamic and not easily determined clinically. The pathophysiological hallmarks of septic shock are cytokine and nitric oxide mediated inflammation, activation of the coagulation cascade, manifesting as myocardial, endothelial, and organ dysfunction (25). Therapeutic targets in the acute management of septic shock are fundamentally aimed at matching oxygen delivery to demand by improving cardiac output for which the key targets are macrovascular.

\section{Circulatory Markers of Shock}

Clinical signs of septic shock such as tachycardia, hypotension, impaired skin perfusion, while readily identifiable and indicative of shock, are difficult to rely upon to indicate hypovolaemia or volume responsiveness. Yet these are commonly the triggers or targets available to clinicians in the first hours of pediatric sepsis management. More advanced tools such as echocardiography or invasive haemodynamic monitoring can assist in deciphering myocardial dysfunction from a hyperdynamic circulation as well as volume responsiveness, however even these, as static measures lack predictive accuracy (39). Their availability are not always available outside of the intensive care environment or during anesthesia. Both dynamic and static measures of volume responsiveness are unreliable in children $(40,41)$ and volume responsiveness as a concept, is somewhat arbitrary. Respiratory variation in aortic blood flow velocities appear better predictors of volume responsiveness in children $(42,43)$ more so than systolic pressure and pulse pressure variation (44) but this is in the context of ventilated children.

Blood pressure and heart rate are the most highly rated clinical signs among pediatric intensivists (45), ED physicians (46), adult intensive care physicians $(47,48)$. Yet blood pressure measured non-invasively are prone to underestimation. A study of over 50,000 concurrent non-invasive and invasive BP measurements showed that NIBP has a poor positive predictive value of $58 \%$ for hypotension meaning over treatment of low blood pressure is possible (49). The quality and volume of the peripheral and central pulses are also critical signs that rely on experience to elucidate and interpret accurately. 
Capillary refill time (CRT) is a simple bedside test universally regarded as a marker of inadequate perfusion and dehydration in children and a specific adjunct sign of shock $(50,51)$. In children with septic shock in intensive care it relates weakly to stroke volume index (52) but commonly relied upon to determine the responsiveness to FBT. A study of adults with septic shock suggest good interrater reliability, good correlation with lactate and SOFA score and 14 day mortality (53) and trials of tissue perfusion-guided therapy (including CRT) on outcomes in sepsis, have ensued (54).

Several studies describe the haemodynamic patterns in children with septic shock, often following an initial dose of FBT commonly referred to as "fluid refractory shock." Deep et al. showed distinct patterns of "cold" (predominantly reduced myocardial function, vasoconstricted) and "warm" (predominantly hyperdynamic, vasodilatory) shock amongst 36 children with community acquired and hospital acquired sepsis with early and sustained abnormalities in haemodynamic values (55). An Indian study in two PICUs showed that in 48 children who had received $40 \mathrm{ml} / \mathrm{kg}$ of FBT the continued presence of both "warm" and "cold" shock based on clinical and echocardiographic indices, was also accompanied by the transformation or evolution over time indicating the dynamic nature of the circulatory disturbance (56). Others have also defined the clinical and haemodynamic phenotypes using a pulmonary artery catheter (57). Ceneviva et al. showed persistence of shock following FBT $(60 \mathrm{ml} / \mathrm{kg})$ in over a third of patients. The distribution of shock patterns were low cardiac index (CI) (58\%), high CI/low systemic vascular resistive index (SVRI) (20\%) and low CI/low SVRI (20\%) (57). Similarly, in another small cohort of children with "fluid refractory shock," non-invasive cardiac output monitoring demonstrated marked differences in physiological patterns between those with catheter related sepsis and community acquired pneumonia (58).

Clearly a spectrum of circulatory phenotypes exists, overlap and evolve in the initial stages of septic shock in children. The ability of clinicians to recognize these entities early and repeatedly on the basis of predominantly clinical signs, commence therapies and use clinical, biochemical, echocardiographic, and perhaps microcirculatory markers to judge response to therapy outlines the complex nature of sepsis resuscitation and teasing out the role of one therapeutic intervention.

\section{Sepsis and the Microcirculation}

Imaging of the microcirculation to measure the number of perfused capillaries and capillary density can assess the microvascular response to sepsis and therapy. It is performed in intensive care patients with a sublingual camera using sidestream dark field video-microscopy of the sublingual circulation. Alterations in the microvasculature include reduction in capillary density and microvascular blood flow $(59,60)$. Microvascular dysregulation that occurs in sepsis include altered rheology of red blood cells, impaired regional vascular autoregulation, activation of coagulation and arteriovenous shunting (60). The microvasculature plays an independent role in tissue perfusion and oxygenation that may not be influenced by macrovascular alterations (61). In an observational study of 18 pediatric sepsis patients, persistent reduction in microcirculatory flow in the first few days of sepsis was associated with mortality (59). In relation to response to $\mathrm{FBT}$, few animal studies using intravital microscopy and video imaging of the microcirculation have shown both improvement as well as persistence in microcirculatory dysfunction with FBT (62) whereas a small observational study in adults with sepsis showed that fluid responders (determined by a $5 \%$ increment in stroke volume), increased capillary density and flow to FBT compared to nonresponders (63). Near-infrared spectroscopy is another noninvasive modality that can assess tissue oxygenation at the bedside and may have a place in assessing the microcirculatory manifestations of septic shock and response to therapy. The clinical utility of measures of the microcirculation in the resuscitation phase of septic shock remains to be seen.

Perhaps, in time, assessment of the phenotypic subtypes of septic shock may extend beyond clinical signs and haemodynamic measured and include genetic markers (64). Until then, the fundamental principles of using a constellation of clinical signs and haemodynamic monitoring in the resuscitation of septic shock with an emphasis on repeated assessments of response to therapy, will remain.

\section{PHYSIOLOGICAL RESPONSES TO FBT}

Pharmacodynamics assessment of FBT in post-operative adults show that the maximal effect on cardiac output occurs at 1.2 mins in responders and the effect dissipates at $10 \mathrm{~min}$ (65). A systematic review of studies looking at haemodynamic responses also support the findings that increases in cardiac output following FBT is unsustained at $30 \mathrm{~min}$ (66). In healthy adult volunteers, rapid IV bolus of $30 \mathrm{ml} / \mathrm{kg}$ of $0.9 \%$ saline and $4 \%$ albumin lead to differences in effects on pulmonary mechanics, inflammation and cardiac preload (67). Specifically, those who received $0.9 \%$ saline had increased pulmonary oedema with an inflammatory component whereas those who received $4 \%$ albumin did not. In adults in an emergency department setting the $5 \%$ changes in HR and BP from baseline measured at $10 \mathrm{~min}$ post $\mathrm{FBT}$ were not sustained at 1 or $2 \mathrm{~h}$ (68). There are limited data on the pharmacodynamic effect of FBT in children. A recent small cohort study however, compared echocardiographic changes in the first $24 \mathrm{~h}$ following FBT and rehydration vs. rehydration alone in malnourished African children with gastroenteritis (69). There were heterogeneous effects on echocardiographic markers of stroke volume in the bolus group; more so when compared to the continuous rehydration group. Long et al. in a prospective observational study showed a transient increase in cardiac index (a product of heart rate and echocardiographic derived stroke volume per meter squared of body surface area; $\left.\mathrm{L} / \mathrm{min} / \mathrm{m}^{2}\right) 5 \mathrm{~min}$ following a fluid bolus that had dissipated by $60 \mathrm{~min}$ to a lower baseline than pre bolus (70). Observational studies such as these are limited by confounding factors but do reflect the reality in clinical practice. It also suggests that that minutely time intervals may be required to understand physiological effects of FBT in a more granular way. The duration, magnitude and dissipation of effect of FBT in children require further examination. 


\section{EVIDENCE BASE AND GUIDELINES FOR FBT IN PEDIATRIC SEPSIS}

The two recent editions of the Surviving Sepsis Campaign Guidelines $(6,71)$ and the ACCM PALS guidelines have not altered their recommendations relating to FBT in sepsis $(5,72)$. They recommend that $20 \mathrm{ml} / \mathrm{kg}$ boluses up to $60 \mathrm{ml} / \mathrm{kg}$ be administered in the first $15 \mathrm{~min}$ of resuscitation unless signs of fluid overload occur. The World Health Organization report on the management of critically ill children, in 2016 recommended that for the treatment of non-specific shock, $10-20 \mathrm{ml}$ of crystalloid be administered between 30 and $60 \mathrm{~min}$ with an emphasis on repeated re-assessments (7). The foundation of these recommendations is largely based on limited human and animal data as well as expert opinion. One of the pivotal observational cohort studies from 1991 investigated the association of fluid administration and mortality in children with septic shock. Thirty four subjects were categorized by administered volumes of FBT in the first hour of septic shock; $<20 \mathrm{ml} / \mathrm{kg}, 20-40 \mathrm{ml} / \mathrm{kg}$ and more than $40 \mathrm{ml} / \mathrm{kg}$ (9). The study showed that those who received $>40 \mathrm{ml} / \mathrm{kg}$ of FBT had improved survival compared to those who received $<20 \mathrm{ml} / \mathrm{kg}$.

There are few randomized studies of FBT in children with septic shock in the context of intensive care resources. Three studies have compared a range of interventions such as fluid types, early inotrope and goal directed therapy with measured outcomes such as shock reversal, mortality, and intensive care resources $(18,73,74)$. These studies included a total of 309 children and when systematically reviewed, there were no discernible difference in patient-centered outcomes (75).

The majority of studies of FBT in children relate to disease specific conditions such as malaria $(76,77)$, dengue fever $(78-80)$, and meningococcal sepsis (81) limiting their broad applicability. Systematic review and meta-analysis of these studies (excluding the FEAST study) do not provide compelling evidence for a mortality benefit from FBT vs. no FBT or for different types of FBT (82).

\section{FLUID EXPANSION AS SUPPORTIVE THERAPY (FEAST) TRIAL}

The FEAST study, a RCT of FBT in over 3,000 Sub-Saharan African children with sepsis and impaired perfusion has been a pivotal study in generating interest in the potential harm from FBT. It showed that boluses of $0.9 \%$ saline or $5 \%$ albumin compared to maintenance fluid significant increased mortality at $48 \mathrm{~h}$ (RR 1.45; 95\% CI 1.13-1.86; $p=0.003$ ). The results were consistent across all pre-specified subgroups including malaria, anemia (hemoglobin concentration $<50 \mathrm{mg} / \mathrm{l}$ ), coma and lactic acidosis (lactate $>5 \mathrm{mmol} / \mathrm{l}$ ). These results generated much interest and debate surrounding the role of FBT in high-income countries (83-85). The investigators assigned causes of death based on clinical features at presentation and concluded that cardiovascular collapse, as the terminal event, was the largest contributor to excess mortality as opposed to pulmonary or neurological failure (86). Important perspectives regarding this trial have been outlined $(84,87)$ but increasing interest in examining FBT has followed in both adults and children. The main limitations of these findings have been well articulated by Duke (87). Firstly, despite being a clearly unwell population of children, shock, defined by the WHO (7) as presence of cold peripheries and weak pulse, tachycardia and delayed capillary refill $>3 \mathrm{~s}$ was not present in around $70 \%$ of participants. Secondly, the lack of availability of intensive care interventions limits the ability to respond to complications of fluid therapy and thirdly, the population studied may well have been at risk of adverse consequences of fluid therapy such as the presence of cerebral oedema, hyponatremia or excessive antidiuretic hormone secretion.

\section{FLUIDS AND HARM: FLUID OVERLOAD}

Fluid accumulation in critical care is recognized as being associated with respiratory and renal morbidity as well as increased ICU Length of stay (LOS) and mortality. The degree to which FBT contributes to fluid accumulation in children is not well established. The association of fluid overload and harm is consistent in a broad spectrum of critically ill children including those following congenital heart disease surgery (88$90)$, acute kidney injury $(91,92)$, acute lung injury (93), children on ECMO (94), in a general PICU $(95,96)$, children with shock (97), and sepsis (98). However, fluid overload is defined, either by percentage of weight accumulation or percentage increase in daily cumulative fluid balance, the association stands in a dose dependant fashion (99). The downstream effects of FBT on fluid accumulation in children with sepsis is likely to represent one of many aetiological factors including non-resuscitation fluid, impaired clearance mechanisms, physiological responses such as SIADH and endothelial dysfunction. Furthermore, how fluid overload (commonly identified from the medical record by net change in fluid input and output) relates to organ oedema, organ perfusion and function, is not clear. Fluid administration is a key modifiable component of fluid accumulation and the impact on organ oedema and function requires further examination.

\section{FLUID RESTRICTIVE RESUSCITATION STRATEGIES}

In response to the concern regarding harm from FBT, studies of restrictive fluid resuscitation have emerged to assess feasibility and safety of early inotrope based resuscitation strategies in adults, in high and low income countries (19, 20, 100). Two pediatric studies exist; one in the UK (23) and one in Canada (22). The UK study randomized 75 children with infections and clinical signs of shock after $20 \mathrm{ml} / \mathrm{kg}$ of FBT to either $10 \mathrm{ml} / \mathrm{kg}$ or $20 \mathrm{ml} / \mathrm{kg}$ per bolus for subsequent boluses. At the end of the 4-h study period the mean difference in FBT volume was $-11.2 \mathrm{ml} / \mathrm{kg}$ (95\% CI -16.6 to $-5.8 \mathrm{~mL} / \mathrm{kg} ; p<$ $0.001)$. Roughly two-thirds received only 1 further bolus. There were no differences in hospital or PICU based outcomes. The authors concluded that lower than expected severity of illness precludes conduct of a larger study. The Canadian study aims to 
determine whether early vasoactive therapy, compared to usual fluid resuscitation practice (up to $60 \mathrm{ml} / \mathrm{kg}$ of isotonic fluid) reduces time to shock reversal and organ dysfunction. Adult data have shown that fluid restrictive resuscitation can reduce FBT administration. The CLASSIC study randomized 151 adults with septic shock and showed a significant reduction of resuscitation fluid at 5 days $[500 \mathrm{ml}$ (IQR;0-2,500) vs. 2,000 ml (IQR; $1,000-4,100) p<0.001]$ but no difference in total administered fluid [12,411 ml (IQR; 5,518-17,035) vs. 13,687 (IQR; 7,16317,082) $p=0.45$ ] but a trend toward lower fluid accumulation $[-1,148(-2,531-235) p=0.06](19)$. Fluid restriction also led to less AKI but no changes in rates of CRRT, respiratory support or mortality. A summary of fluid restrictive resuscitation studies in children and adults with sepsis is in Supplementary Table 1.

For pediatric studies focusing on fluid restriction it will be important to determine feasibility of implementation of a fluid restriction protocol in terms of recruitment and separation between the groups for dose of FBT. Whether restrictive FBT can present a safe, feasible alternative that positively impacts patient centered outcomes is the challenge for these studies.

\section{CHALLENGES OF STUDYING INTERVENTIONS IN PEDIATRIC SEPSIS: FUTURE DIRECTIONS}

The time critical nature of recognizing and initiating management of pediatric septic shock belies the challenges of investigating FBT. Determining triggers and targets for interventions will largely rely on haemodynamic markers of shock as well as markers of impaired tissue perfusion such as hyperlactataemia. Despite the inherent difficulties, alternative interventions may prove to be safe equivalent in reversing shock and may reduce harm in terms of morbidity and mortality related to limiting excessive fluid administration. One such strategy is restrictive fluid resuscitation where early vasoactive therapy is initiated rather than repeated FBT.

\section{Population}

Targeting children with septic shock would be necessary despite the challenges in recognizing this group early at presentation. A combination of haemodynamic indicators as well as features of organ dysfunction (altered consciousness state, tachypnoea) and tissue dysoxia (lactate elevation) are key features. A study in ANZ showed that these features are easily identifiable early and can accurately discriminate children at risk of death, albeit once admitted to an intensive care unit (30). Recent international consensus definition of sepsis severity (101) specifically recognize markers of organ dysfunction to identify high risk groups but are not designed for children. The range in age specific normal values will necessitate sophisticated trial infrastructure to ensure protocol adherence and appropriate recruitment.

\section{Intervention}

Trials of restrictive fluid therapy will require a clinically significant separation of administered fluid volume. Vasoactive agents such as adrenaline or noradrenaline can be administered peripherally and are suitable alternate interventions. Adrenaline being more inotropic with vasoconstrictor activity would be the optimal agent. In most instances, central venous access would not be readily available and hence dilute peripheral administration would be required. The administration of peripheral adrenaline presents several issues warranting consideration. Initial titration of adrenaline would occur using non-invasive blood pressure monitoring and, in the presence of shock, would require clear pathways and ceiling doses to either enable weaning or mandate early intensive care interventions. The entry point of recruitment would need to occur when initial therapy for reversing shock are insufficient. Otherwise one risks exposing a large group of children to an intervention (or comparison therapy) that may not have been indicated thereby exposing a proportion of children to excessive therapy. The presence of septic shock and administration of $20 \mathrm{ml} / \mathrm{kg}$ of FBT and a decision to administer further resuscitation would be an example of suitable inclusion criteria.

\section{Outcomes}

Appropriate outcomes for studies of FBT in sepsis will be an important consideration for trial designs. The desired range of outcomes should include mortality, measures of organ dysfunction, need for intensive care resources as well as outcomes specific to fluid therapy. Markers of tissue oxygenation, tissue oedema and endothelial dysfunction have also been included as secondary endpoints in current study designs. The sample size required to show a $5-10 \%$ difference in outcomes have been suggested to be up to 1,500 participants (1) which would be feasibly achieved by a multinational collaboration.

\section{CONCLUSIONS}

FBT has been the frontline recommended therapy in sepsis management guidelines for several decades without a body of evidence supporting its appropriate use. Increasing attention has now turned to the potential consequences of excessive fluid therapy in the context of evidence suggesting harm. This has made the time ripe to further investigate the role of this long standing, fundamental intervention in pediatric sepsis. Restrictive fluid resuscitation is currently at the forefront of alternative strategies being investigated. Whether this approach is safe, feasible and effective in reducing excessive fluid therapy and can be shown to independently improve meaningful outcomes in children with septic shock remains to be seen.

\section{AUTHOR CONTRIBUTIONS}

The author confirms being the sole contributor of this work and has approved it for publication.

\section{SUPPLEMENTARY MATERIAL}

The Supplementary Material for this article can be found online at: https://www.frontiersin.org/articles/10.3389/fped. 2018.00308/full\#supplementary-material 


\section{REFERENCES}

1. Weiss SL, Fitzgerald JC, Pappachan J, Wheeler D, Jaramillo-Bustamante JC, Salloo A, et al. Global epidemiology of pediatric severe sepsis: the sepsis prevalence, outcomes, and therapies study. Am J Respir Crit Care Med. (2015) 191:1147-57. doi: 10.1164/rccm.201412-2323OC

2. Ruth A, McCracken CE, Fortenberry JD, Hall M, Simon HK, Hebbar KB. Pediatric severe sepsis: current trends and outcomes from the Pediatric Health Information Systems database. Pediatr Crit Care Med. (2014) 15:82838. doi: $10.1097 /$ pcc.0000000000000254

3. Wolfler A, Silvani P, Musicco M, Antonelli M, Salvo I, Italian Pediatric Sepsis Study g. Incidence of and mortality due to sepsis, severe sepsis and septic shock in Italian Pediatric Intensive Care Units: a prospective national survey. Intens Care Med. (2008) 34:1690-7. doi: 10.1007/s00134-008-1148-y

4. Carcillo JA, Fields AI, American College of Critical Care Medicine Task Force Committee M. Clinical practice parameters for hemodynamic support of pediatric and neonatal patients in septic shock. Crit Care Med. (2002) 30:1365-78.

5. Davis AL, Carcillo JA, Aneja RK, Deymann AJ, Lin JC, Nguyen TC, et al. American College of critical care medicine clinical practice parameters for hemodynamic support of pediatric and neonatal septic shock.Crit Care Med. (2017) 45:1061-93. doi: 10.1097/ccm.0000000000002425

6. Rhodes A, Evans LE, Alhazzani W, Levy MM, Antonelli M, Ferrer R, et al. Surviving sepsis campaign: International Guidelines for Management of Sepsis and Septic Shock: 2016. Crit Care Med. (2017) 45:486-552. doi: 10.1007/s00134-017-4683-6

7. Updated Guideline: Paediatric Emrgency Triage, Assessment and Treatment. Geneva: World Health Organisation (2016).

8. Levy MM, Evans LE, Rhodes A. The surviving sepsis campaign bundle: 2018 update. Intens Care Med. (2018) 44:925-8. doi: 10.1007/s00134-018-5085-0

9. Carcillo JA, Davis AL, Zaritsky A. Role of early fluid resuscitation in pediatric septic shock. JAMA (1991) 266:1242-5.

10. Ottosson J, Dawidson I, Brandberg A, Idvall J, Sandor Z. Cardiac output and organ blood flow in experimental septic shock: effect of treatment with antibiotics, corticosteroids, and fluid infusion. Circ Shock (1991) 35:14-24.

11. Carroll GC, Snyder JV. Hyperdynamic severe intravascular sepsis depends on fluid administration in cynomolgus monkey. Am J Physiol. (1982) 243:R131-41.

12. Inwald DP, Tasker RC, Peters MJ, Nadel S, Paediatric Intensive Care Society Study G. Emergency management of children with severe sepsis in the United Kingdom: the results of the Paediatric Intensive Care Society sepsis audit. Arch Dis Child. (2009) 94:348-53. doi: 10.1136/adc.2008.153064

13. Paul R, Neuman MI, Monuteaux MC, Melendez E. Adherence to PALS sepsis guidelines and hospital length of stay. Pediatrics (2012) 130:e273-80. doi: 10.1542/peds.2012-0094

14. Investigators TSS. A comparison of albumin and saline for fluid resuscitation in the intensive care unit. N Engl J Med. (2004) 350:2247-56. doi: 10.1056/NEJMoa040232

15. Semler MW, Self WH, Wanderer JP, Ehrenfeld JM, Wang L, Byrne DW, et al. Balanced crystalloids versus saline in critically ill adults. N Engl J Med. (2018) 378:829-39. doi: 10.1056/NEJMoa1711584

16. Investigators A, Group ACT, Peake SL, Delaney A, Bailey M, Bellomo R, et al. Goal-directed resuscitation for patients with early septic shock. N Engl J Med. (2014) 371:1496-506. doi: 10.1056/NEJMoa1404380

17. Pro CI, Yealy DM, Kellum JA, Huang DT, Barnato AE, Weissfeld LA, et al. A randomized trial of protocol-based care for early septic shock. $N$ Engl J Med. (2014) 370:1683-93. doi: 10.1056/NEJMoa1401602

18. de Oliveira CF, de Oliveira DS, Gottschald AF, Moura JD, Costa GA, Ventura AC, et al. ACCM/PALS haemodynamic support guidelines for paediatric septic shock: an outcomes comparison with and without monitoring central venous oxygen saturation. Intens Care Med. (2008) 34:1065-75. doi: 10.1007/s00134-008-1085-9

19. Hjortrup PB, Haase N, Bundgaard H, Thomsen SL, Winding R, Pettila $\mathrm{V}$, et al. Restricting volumes of resuscitation fluid in adults with septic shock after initial management: the CLASSIC randomised, parallelgroup, multicentre feasibility trial. Intens Care Med. (2016) 42:1695-705. doi: $10.1007 /$ s00134-016-4500-7
20. Macdonald SPJ, Taylor DM, Keijzers G, Arendts G, Fatovich DM, Kinnear FB, et al. REstricted Fluid REsuscitation in Sepsis-associated Hypotension (REFRESH): study protocol for a pilot randomised controlled trial. Trials (2017) 18:399. doi: 10.1186/s13063-017-2137-7

21. O'Hara CB, Canter RR, Mouncey PR, Carter A, Jones N, Nadel S, et al. A qualitative feasibility study to inform a randomised controlled trial of fluid bolus therapy in septic shock. Arch Dis Childh. (2018) 103:28-32. doi: 10.1136/archdischild-2016-312515

22. Parker MJ, Thabane L, Fox-Robichaud A, Liaw P, Choong K. A trial to determine whether septic shock-reversal is quicker in pediatric patients randomized to an early goal-directed fluid-sparing strategy versus usual care (SQUEEZE): study protocol for a pilot randomized controlled trial. Trials (2016) 17:556. doi: 10.1186/s13063-016-1689-2

23. Inwald DP, Canter R, Woolfall K, Mouncey P, Zenasni Z, O'Hara $\mathrm{C}$, et al. Restricted fluid bolus volume in early septic shock: results of the Fluids in Shock pilot trial. Arch Dis Childh. (2018). doi: 10.1136/archdischild-2018-314924

24. Maitland K, Kiguli S, Opoka RO, Engoru C, Olupot-Olupot P, Akech SO, et al. Mortality after fluid bolus in African children with severe infection. N Engl J Med. (2011) 364:2483-95. doi: 10.1056/NEJMoa1101549

25. Greer JR. Pathophysiology of cardiovascular dysfunction in sepsis. BJA Educ. (2015) 15:316-21. doi: 10.1093/bjaceaccp/mkv003

26. Lane RD, Funai T, Reeder R, Larsen GY. High reliability pediatric septic shock quality improvement initiative and decreasing mortality. Pediatrics (2016) 138:e20154153. doi: 10.1542/peds.2015-4153

27. Boeddha NP, Schlapbach LJ, Driessen GJ, Herberg JA, Rivero-Calle I, CebeyLópez M, et al. Mortality and morbidity in community-acquired sepsis in European pediatric intensive care units: a prospective cohort study from the European Childhood Life-threatening Infectious Disease Study (EUCLIDS). Crit Care (2018) 22:143. doi: 10.1186/s13054-018-2052-7

28. Schlapbach LJ, Straney L, Alexander J, MacLaren G, Festa M, Schibler A, et al. Mortality related to invasive infections, sepsis, and septic shock in critically ill children in Australia and New Zealand, 2002-13: a multicentre retrospective cohort study. Lancet Infect Dis. (2015) 15:46-54. doi: 10.1016/S1473-3099(14)71003-5

29. Weiss SL, Balamuth F, Hensley J, Fitzgerald JC, Bush J, Nadkarni VM, et al. The epidemiology of hospital death following pediatric severe sepsis: when, why, and how children with sepsis die. Pediatr Crit Care Med. (2017) 18:823-30. doi: 10.1097/PCC.0000000000001222

30. Schlapbach LJ, MacLaren G, Festa M, Alexander J, Erickson S, Beca J, et al. Prediction of pediatric sepsis mortality within $1 \mathrm{~h}$ of intensive care admission. Intens Care Med. (2017) 43:1085-96. doi: 10.1007/s00134-017-4701-8

31. Akech S, Ledermann H, Maitland K. Choice of fluids for resuscitation in children with severe infection and shock: systematic review. BMJ (2010) 341:c4416. doi: 10.1136/bmj.c4416

32. Opiyo N, Molyneux E, Sinclair D, Garner P, English M. Immediate fluid management of children with severe febrile illness and signs of impaired circulation in low-income settings: a contextualised systematic review. BMJ Open (2014) 4:e004934. doi: 10.1136/bmjopen-2014-004934

33. Han YY, Carcillo JA, Dragotta MA, Bills DM, Watson RS, Westerman $\mathrm{ME}$, et al. Early reversal of pediatric-neonatal septic shock by community physicians is associated with improved outcome. Pediatrics (2003) 112:793-9.

34. Oliveira CF, Nogueira de Sa FR, Oliveira DS, Gottschald AF, Moura JD, Shibata AR, et al. Time- and fluid-sensitive resuscitation for hemodynamic support of children in septic shock: barriers to the implementation of the American College of Critical Care Medicine/Pediatric Advanced Life Support Guidelines in a pediatric intensive care unit in a developing world. Pediatr Emerg Care. (2008) 24:810-5. doi: 10.1097/PEC.0b013e31818e9f3a

35. Larsen GY, Mecham N, Greenberg R. An emergency department septic shock protocol and care guideline for children initiated at triage. Pediatrics (2011) 127:e1585-92.

36. Cruz AT, Perry AM, Williams EA, Graf JM, Wuestner ER, Patel B. Implementation of goal-directed therapy for children with suspected sepsis in the emergency department. Pediatrics (2011) 127:e758-66. doi: 10.1542/peds.2010-2895 
37. Marik PE, Linde-Zwirble WT, Bittner EA, Sahatjian J, Hansell D. Fluid administration in severe sepsis and septic shock, patterns and outcomes: an analysis of a large national database. Intens Care Med. (2017) 43:625-32. doi: 10.1007/s00134-016-4675-y

38. Leisman DE, Goldman C, Doerfler ME, Masick KD, Dries S, Hamilton E, et al. Patterns and outcomes associated with timeliness of initial crystalloid resuscitation in a prospective sepsis and septic shock cohort. Crit Care Med. (2017) 45:1596-606. doi: 10.1097/ccm.0000000000002574

39. Cecconi M, De Backer D, Antonelli M, Beale R, Bakker J, Hofer C, et al. Consensus on circulatory shock and hemodynamic monitoring. Task force of the European Society of Intensive Care Medicine. Intens Care Med. (2014) 40:1795-815. doi: 10.1007/s00134-014-3525-Z

40. Gan H, Cannesson M, Chandler JR, Ansermino JM. Predicting fluid responsiveness in children: a systematic review. Anesth Analges. (2013) 117:1380-92. doi: 10.1213/ANE.0b013e3182a9557e

41. Saxena R, Durward A, Steeley S, Murdoch IA, Tibby SM. Predicting fluid responsiveness in 100 critically ill children: the effect of baseline contractility. Intens Care Med. (2015) 41:2161-9. doi: 10.1007/s00134-015-4075-8

42. Choi DY, Kwak HJ, Park HY, Kim YB, Choi CH, Lee JY. Respiratory variation in aortic blood flow velocity as a predictor of fluid responsiveness in children after repair of ventricular septal defect. Pediatr Cardiol. (2010) 31:1166-70. doi: 10.1007/s00246-010-9776-8

43. Desgranges FP, Desebbe O, Pereira de Souza Neto E, Raphael D, Chassard D. Respiratory variation in aortic blood flow peak velocity to predict fluid responsiveness in mechanically ventilated children: a systematic review and meta-analysis. Paediatr Anaesth. (2016) 26:37-47. doi: 10.1111/pan.12803

44. Durand P, Chevret L, Essouri S, Haas V, Devictor D. Respiratory variations in aortic blood flow predict fluid responsiveness in ventilated children. Intens Care Med. (2008) 34:888-94. doi: 10.1007/s00134-008-1021-z

45. Gelbart B, Schlapbach L, Ganeshalingham A, Ganu S, Erickson S, Oberender F, et al. Fluid bolus therapy in critically ill children: a survey of practice among paediatric intensive care doctors in Australia and New Zealand. Crit Care Resusc. (2018) 20:131-8.

46. Long E, Babl F, Dalziel S, Dalton S, Etheridge C, Duke T, et al. Fluid resuscitation for paediatric sepsis: a survey of senior emergency physicians in Australia and New Zealand. Emerg Med Australas. (2015) 27:245-50. doi: 10.1111/1742-6723.12400

47. Glassford NJ, Jones SL, Martensson J, Eastwoods GM, Bailey M, Cross AM, et al. Characteristics and expectations of fluid bolus therapy: a bi-national survey of acute care physicians. Anaesth Intens Care (2015) 43:750-6.

48. Cecconi M, Hofer C, Teboul JL, Pettila V, Wilkman E, Molnar Z, et al. Fluid challenges in intensive care: the FENICE study : a global inception cohort study. Intens Care Med. (2015) 41:1529-37. doi: 10.1007/s00134-015-3850-x

49. Ray S, Rogers L, Noren DP, Dhar R, Nadel S, Peters MJ, et al. Risk of over-diagnosis of hypotension in children: a comparative analysis of over 50,000 blood pressure measurements. Intensive Care Med. (2017) 43:1540-1. doi: 10.1007/s00134-017-4843-8

50. Carcillo JA. Capillary refill time is a very useful clinical sign in early recognition and treatment of very sick children. Pediatr Crit Care Med. (2012) 13:210-2. doi: 10.1097/PCC.0b013e3182231667

51. Fleming S, Gill P, Jones C, Taylor JA, Van den Bruel A, Heneghan C, et al. The diagnostic value of capillary refill time for detecting serious illness in children: a systematic review and meta-analysis. PLoS ONE (2015) 10:e0138155. doi: 10.1371/journal.pone.0138155

52. Tibby SM, Hatherill M, Murdoch IA. Capillary refill and core-peripheral temperature gap as indicators of haemodynamic status in paediatric intensive care patients. Arch Dis Child. (1999) 80:163-6.

53. Ait-Oufella H, Bige N, Boelle PY, Pichereau C, Alves M, Bertinchamp R, et al. Capillary refill time exploration during septic shock. Intens Care Med. (2014) 40:958-64. doi: 10.1007/s00134-014-3326-4

54. Pettila V, Merz T, Wilkman E, Perner A, Karlsson S, Lange T, et al. Targeted tissue perfusion versus macrocirculation-guided standard care in patients with septic shock (TARTARE-2S): study protocol and statistical analysis plan for a randomized controlled trial. Trials (2016) 17:384. doi: 10.1186/s13063-016-1515-X

55. Deep A, Goonasekera CD, Wang Y, Brierley J. Evolution of haemodynamics and outcome of fluid-refractory septic shock in children. Intens Care Med. (2013) 39:1602-9. doi: 10.1007/s00134-013-3003-z
56. Ranjit S, Aram G, Kissoon N, Ali MK, Natraj R, Shresti S, et al. Multimodal monitoring for hemodynamic categorization and management of pediatric septic shock: a pilot observational study*. Pediatr Crit Care Med. (2014) 15:e17-26. doi: 10.1097/PCC.0b013e3182a5589c

57. Ceneviva G, Paschall JA, Maffei F, Carcillo JA. Hemodynamic support in fluid-refractory pediatric septic shock. Pediatrics (1998) 102:e19.

58. Brierley J, Peters MJ. Distinct hemodynamic patterns of septic shock at presentation to pediatric intensive care. Pediatrics (2008) 122:752-9. doi: 10.1542/peds.2007-1979

59. Top AP, Ince C, de Meij N, van Dijk M, Tibboel D. Persistent low microcirculatory vessel density in nonsurvivors of sepsis in pediatric intensive care. Crit Care Med. (2011) 39:8-13. doi: 10.1097/CCM.0b013e3181fb7994

60. Spronk PE, Zandstra DF, Ince C. Bench-to-bedside review: sepsis is a disease of the microcirculation. Crit Care (2004) 8:462-8. doi: 10.1186/cc2894

61. Boerma EC, Ince $\mathrm{C}$. The role of vasoactive agents in the resuscitation of microvascular perfusion and tissue oxygenation in critically ill patients. Intens Care Med. (2010) 36:2004-18. doi: 10.1007/s00134-010-1970-x

62. Obonyo NG, Fanning JP, Ng ASY, Pimenta LP, Shekar K, Platts DG, et al. Effects of volume resuscitation on the microcirculation in animal models of lipopolysaccharide sepsis: a systematic review. Intens Care Med Exp. (2016) 4:38. doi: 10.1186/s40635-016-0112-3

63. Klijn E, van Velzen MH, Lima AP, Bakker J, van Bommel J, Groeneveld $\mathrm{AB}$. Tissue perfusion and oxygenation to monitor fluid responsiveness in critically ill, septic patients after initial resuscitation: a prospective observational study. J Clin Monitor Comput. (2015) 29:707-12. doi: 10.1007/s10877-014-9653-8

64. Wong HR. Genetics and genomics in pediatric septic shock. Crit Care Med. (2012) 40:1618-26. doi: 10.1097/CCM.0b013e318246b546

65. Aya HD, Ster IC, Fletcher N, Grounds RM, Rhodes A, Cecconi M. Pharmacodynamic analysis of a fluid challenge. Crit Care Med. (2016) 44:880-91. doi: 10.1097/CCM.0000000000001517

66. Glassford NJ, Eastwood GM, Bellomo R. Physiological changes after fluid bolus therapy in sepsis: a systematic review of contemporary data. Crit Care (2014) 18:696. doi: 10.1186/s13054-014-0696-5

67. Bihari S, Wiersema UF, Schembri D, De Pasquale CG, Dixon DL, Prakash $\mathrm{S}$, et al. Bolus intravenous $0.9 \%$ saline, but not $4 \%$ albumin or $5 \%$ glucose, causes interstitial pulmonary edema in healthy subjects. J Appl Physiol. (2015) 119:783-92. doi: 10.1152/japplphysiol.00356.2015

68. Bihari S, Teubner DJ, Prakash S, Beatty T, Morphett M, Bellomo $\mathrm{R}$, et al. Fluid bolus therapy in emergency department patients: indications and physiological changes. Emerg Med Aust. (2016) 28:531-7. doi: $10.1111 / 1742-6723.12621$

69. Obonyo N, Brent B, Olupot-Olupot P, Boele van Hensbroek M, Kuipers I, Wong S, et al. Myocardial and haemodynamic responses to two fluid regimens in African children with severe malnutrition and hypovolaemic shock (AFRIM study). Crit Care (2017) 21:103. doi: 10.1186/s13054-017-1679-0

70. Long E, Babl FE, Oakley E, Sheridan B, Duke T, Pediatric Research in Emergency Departments International C. Cardiac index changes with fluid bolus therapy in children with sepsis-an observational study. Pediatr Crit Care Med. (2018) 19:513-8. doi: 10.1097/PCC.00000000000 01534

71. Dellinger RP, Levy MM, Rhodes A, Annane D, Gerlach H, Opal SM, et al. Surviving Sepsis Campaign: international guidelines for management of severe sepsis and septic shock, 2012. Intens Care Med. (2013) 39:165-228. doi: 10.1007/s00134-012-2769-8

72. Brierley J, Carcillo JA, Choong K, Cornell T, Decaen A, Deymann A, et al. Clinical practice parameters for hemodynamic support of pediatric and neonatal septic shock: 2007 update from the American College of Critical Care Medicine.[Erratum appears in Crit Care Med. 2009 Apr;37:1536 Note: Skache, Sara [corrected to Kache, Saraswati]; Irazusta, Jose [corrected to Irazuzta, Jose]]. Crit Care Med. (2009) 37:666-88. doi: 10.1097/CCM.0b013e31819323c6

73. Upadhyay M, Singhi S, Murlidharan J, Kaur N, Majumdar S. Randomized evaluation of fluid resuscitation with crystalloid (saline) and colloid (polymer from degraded gelatin in saline) in pediatric septic shock. Indian Pediatr. (2005) 42:223-31. 
74. Santhanam I, Sangareddi S, Venkataraman S, Kissoon N, Thiruvengadamudayan V, Kasthuri RK. A prospective randomized controlled study of two fluid regimens in the initial management of septic shock in the emergency department. Pediatr Emerg Care (2008) 24:647-55. doi: 10.1097/PEC.0b013e31818 $844 \mathrm{cf}$

75. Gelbart B, Glassford NJ, Bellomo R. Fluid bolus therapy-based resuscitation for severe sepsis in hospitalized children: a systematic review. Pediatr Crit Care Med. (2015) 16:e297-307. doi: 10.1097/PCC.00000000000 00507

76. Akech S, Gwer S, Idro R, Fegan G, Eziefula AC, Newton CRJC, et al. Volume expansion with albumin compared to gelofusine in children with severe malaria: results of a controlled trial. PLOS Clin Trial (2006) 1:e21. doi: 10.1371/journal.pctr.0010021

77. Maitland K, Pamba A, English M, Peshu N, Marsh K, Newton C, et al. Randomized trial of volume expansion with albumin or saline in children with severe malaria: preliminary evidence of albumin benefit. Clin Infect Dis. (2005) 40:538-45. doi: 10.1086/427505

78. Dung NM, Day NP, Tam DT, Loan HT, Chau HT, Minh LN, et al. Fluid replacement in dengue shock syndrome: a randomized, double-blind comparison of four intravenous-fluid regimens. Clin Infect Dis. (1999) 29:787-94.

79. Ngo NT, Cao XT, Kneen R, Wills B, Nguyen VM, Nguyen TQ, et al. Acute management of dengue shock syndrome: a randomized double-blind comparison of 4 intravenous fluid regimens in the first hour. Clin Infect Dis. (2001) 32:204-13. doi: 10.1086/318479

80. Wills BA, Nguyen MD, Ha TL, Dong TH, Tran TN, Le TT, et al. Comparison of three fluid solutions for resuscitation in dengue shock syndrome. $\mathrm{N} \mathrm{Engl} \mathrm{J}$ Med. (2005) 353:877-89. doi: 10.1056/NEJMoa044057

81. Booy R, Habibi P, Nadel S, de Munter C, Britto J, Morrison A, et al. Reduction in case fatality rate from meningococcal disease associated with improved healthcare delivery. Arch Dis Child. (2001) 85:386-90. doi: $10.1136 /$ adc.85.5.386

82. Ford N, Hargreaves S, Shanks L. Mortality after fluid bolus in children with shock due to sepsis or severe infection: a systematic review and meta-analysis. PLoS ONE (2012) 7:e43953. doi: 10.1371/journal.pone.00 43953

83. Hilton AK, Bellomo R. A critique of fluid bolus resuscitation in severe sepsis. Crit Care (2012) 16:302. doi: 10.1186/cc11154

84. Brewster D. African fluid bolus study: implications for practice. J Paediatr Child Health (2012) 48:548-50. doi: 10.1111/j.1440-1754.2012.02431.x

85. Myburgh J, Finfer S. Causes of death after fluid bolus resuscitation: new insights from FEAST. BMC Med. (2013) 11:67. doi: 10.1186/1741-7015-11-67

86. Maitland K, George EC, Evans JA, Kiguli S, Olupot-Olupot P, Akech $\mathrm{SO}$, et al. Exploring mechanisms of excess mortality with early fluid resuscitation: insights from the FEAST trial. BMC Med. (2013) 11:68. doi: 10.1186/1741-7015-11-68

87. Duke T. What the African fluid-bolus trial means. Lancet (2011) 378:1685-7. doi: 10.1016/S0140-6736\%2811\%2960881-7

88. Hazle MA, Gajarski RJ, Yu S, Donohue J, Blatt NB. Fluid overload in infants following congenital heart surgery. Pediatric Crit Care Med.. (2013) 14:44-9. doi: 10.1097/PCC.0b013e3182712799

89. Piggott KD, Soni M, Decampli WM, Ramirez JA, Holbein D, Fakioglu H, et al. Acute kidney injury and fluid overload in neonates following surgery for congenital heart disease. World J Pediatric Congen Heart Surg. (2015) 6:401-6. doi: 10.1177/2150135115586814
90. Stein A, de Souza L, Belettini C, Menegazzo W, Viegas J, Costa Pereira E. Fluid overload and changes in serum creatinine after cardiac surgery: predictors of mortality and longer intensive care stay. A prospective cohort study. Crit Care (2012) 16:R99. doi: 10.1186/cc11368

91. Foland J, Fortenberry J, Warshaw B, Pettignano R, Merritt R, Heard M. Fluid overload before continuous hemofiltration and survival in critically ill children: a retrospective analysis. Crit Care Med. (2004) 32:1771-6. doi: 10.1097/01.CCM.0000132897.52737.49

92. Li Y, Wang J, Bai Z, Chen J, Wang X, Pan J, et al. Early fluid overload is associated with acute kidney injury and PICU mortality in critically ill children. Eur J Pediatr. (2016) 175:39-48. doi: 10.1007/s00431-015-2592-7

93. Valentine SL, Sapru A, Higgerson RA, Spinella PC, Flori HR, Graham DA, et al. Fluid balance in critically ill children with acute lung injury. Crit Care Med. (2012) 40:2883-9. doi: 10.1097/CCM.0b013e31825bc54d

94. Selewski DT, Askenazi DJ, Bridges BC, Cooper DS, Fleming GM, Paden ML, et al. The impact of fluid overload on outcomes in children treated with extracorporeal membrane oxygenation: a multicenter retrospective cohort study*. Pediatric Crit Care Med. (2017) 18:1126-35. doi: $10.1097 /$ pcc.0000000000001349

95. Arikan AA, Zappitelli M, Goldstein SL, Naipaul A, Jefferson LS, Loftis LL. Fluid overload is associated with impaired oxygenation and morbidity in critically ill children. Pediatric Crit Care Med. (2012) 13:253-8. doi: 10.1097/PCC.0b013e31822882a3

96. Sinitsky L, Walls D, Nadel S, Inwald DP. Fluid overload at 48 hours is associated with respiratory morbidity but not mortality in a general PICU: retrospective cohort study*. Pediatric Crit Care Med. (2015) 16:205-9. doi: $10.1097 /$ pcc.0000000000000318

97. Bhaskar P, Dhar AV, Thompson M, Quigley R, Modem V. Early fluid accumulation in children with shock and ICU mortality: a matched case-control study. Intens Care Med. (2015) 41:1445-53. doi: 10.1007/s00134-015-3851-9

98. Chen J, Li X, Bai Z, Fang F, Hua J, Li Y, et al. Association of fluid accumulation with clinical outcomes in critically ill children with severe sepsis. PLoS ONE (2016) 11:e0160093. doi: 10.1371/journal.pone.0160093

99. Alobaidi R, Morgan C, Basu RK, Stenson E, Featherstone R, Majumdar SR, et al. Association between fluid balance and outcomes in critically ill children: A systematic review and meta-analysis. JAMA Pediatr. (2018) 172:257-68. doi: 10.1001/jamapediatrics.2017.4540

100. Andrews B, Semler MW, Muchemwa L, Kelly P, Lakhi S, Heimburger DC, et al. Effect of an early resuscitation protocol on in-hospital mortality among adults with sepsis and hypotension: a randomized clinical trial. JAMA (2017) 318:1233-40. doi: 10.1001/jama.2017.10913

101. Singer M, Deutschman CS, Seymour CW, Shankar-Hari M, Annane D, Bauer $\mathrm{M}$, et al. The third international consensus definitions for sepsis and septic shock (sepsis-3). JAMA (2016) 315:801-10. doi: 10.1001/jama.2016.0287

Conflict of Interest Statement: The author declares that the research was conducted in the absence of any commercial or financial relationships that could be construed as a potential conflict of interest.

Copyright (C) 2018 Gelbart. This is an open-access article distributed under the terms of the Creative Commons Attribution License (CC BY). The use, distribution or reproduction in other forums is permitted, provided the original author(s) and the copyright owner(s) are credited and that the original publication in this journal is cited, in accordance with accepted academic practice. No use, distribution or reproduction is permitted which does not comply with these terms. 